\title{
Characteristics of Inference and Error in 4-6 Grade Students with Reading Comprehension Difficulties
}

\author{
Kyung-Jin Yu, ${ }^{a}$, Mibae Kim ${ }^{\mathrm{b}}$ \\ ${ }^{a}$ Department of Speech, Hearing and Language Therapy, Graduate School, Catholic University of Pusan, Busan, Korea \\ ${ }^{b}$ Department of Speech, Hearing and Language Therapy, Catholic University of Pusan, Busan, Korea
}

Correspondence: Mibae Kim, $\mathrm{PhD}$

Department of Speech, Hearing and Language Thearpy, Catholic University of Pusan, 57

Oryundae-ro, Geumjeong-gu, Busan 46252, Korea Tel: +82-51-510-0845

Fax: +82-51-510-0848

E-mail: mbkim@cup.ac.kr

Received: April 5, 2017

Revised: May 8, 2017

Accepted: May 24, 2017

This work is based on the master's thesis of the first author.

\begin{abstract}
Objectives: The purpose of this study is to evaluate the characteristics of inference in 4-6 grade students with reading comprehension difficulties. In addition, we have identified error patterns of inference skills in reading. Methods: A total of 38 students (19 children with reading comprehension difficulties and 19 normally developing children) participated in the study. The tasks evaluating the characteristics of inference were composed of 4 texts and 45 questions (literal information, cohesive inference, knowledge based inference, evaluative inference, elaborative inference). Results: First, the inference ability of children with reading comprehension difficulties was significantly lower than that of the normally developing children. Second, performance in characteristics of inference was significantly different. Third, there was an interaction effect between the reading groups and the characteristics of inference displayed. Fourth, the error patterns in both reading groups appeared similar. In both reading groups the error patterns of 'wrong inferences' and 'immature inferences' appeared more than $50 \%$ of the time. However, children with reading comprehension difficulties showed higher rates of 'failure of literal comprehension' than the normally developing children. Conclusion: The results demonstrated that children with reading comprehension difficulties had difficulties in inference tasks in reading. It seems necessary to examine inference tasks in reading to provide an intervention program for children with reading comprehension difficulties.
\end{abstract}

Keywords: Reading difficulties, Reading comprehension, Inference, Type of inference, Error pattern
읽기는 의사소통의 수단이자 학습의 도구가 되는 능력으로 여러 가지 능력과 지식이 융합된 것이다. 읽기를 성취하기 위해서는 크게 해독(decoding)과 언어적 이해(linguistic comprehension)가 필요 하다(Hoover \& Gough, 1990). 해독이 자동화되는 시기를 거치고 읽기가 점차 유창해지는 초등 고학년이 되면 독자는 읽기이해에 초 점을 두게 된다. 초등 고학년이 되면 '읽기를 배우는 단계'가 아닌 읽기를 통해서 새로운 정보를 습득하는 '배우기 위해 읽는 단계'에 도달한다(Chall, 1983). 배우기 위해 읽는 단계에서는 해독보다 언 어능력이 더 중요하다. 언어능력을 바탕으로 글 속에 있는 정보를 확인하고 언어적 지식을 활용하여 내용을 구체화 할 수 있다. 또한 이 단계에 이르러서는 텍스트에 없는 내용을 도출할 수 있고 이러 한 읽기를 심층적 읽기이해라고 한다.
읽기이해를 설명하는 동심원 읽기 모형(A Heuristic for Thinking About Reading Comprehension; Snow, 2010)에서는 4가지 점 차 확장되는 원들로 읽기이해를 설명하고 있었다. 첫 번째 가장 작 은 원은 단어수준의 읽기로 해독을 말한다. 이를 포함한 두 번째 원 은 글에 기초한 의미 구성이 가능한 핵심적인 이해과정을 말한다. 이 때 글 내용 기억, 글에 기초한 추론 및 텍스트 정보와 세상사 지 식을 연결하는 능력이 필요하다고 한다. 더 확장된 세 번째 원은 글 에 기초한 이해를 넘어선 이해로, 심층적인 읽기이해가 가능한 단 계를 말한다. 이 단계는 초등 고학년부터 가능하며 글 내용의 이해, 배경지식, 추론과 이러한 요소들을 통합하는 능력이 필요하다. 동 심원 모형에서 가장 큰 네 번째 원은 정교한 이해과정으로, 글을 읽 고 심층적 학습을 하거나 글 내용을 바탕으로 학문적인 연구를 할 
수 있는 단계를 말한다. 이 단계에서 독자는 풍부한 읽기 경험을 토 대로 폭넓은 배경지식을 보유하고 있어 글을 읽으면서 비평을 할 수 있다. 동심원 읽기이해 모형에서도 볼 수 있듯이 심층적인 읽기 이해는 텍스트 내의 정보만을 파악하는 것이 아니라 이외의 새로 운 정보를 도출하는 것까지 포함한다. 글 속에 없는 내용을 도출해 야 하기 때문에 사건을 연결하고 다음 사건을 예측해보는 것들이 필수적이다. 따라서 심층적인 읽기이해 기초는 추론능력이라고 할 수 있다(Cain \& Oakhill, 2007; Kamhi \& Catts, 2012; Snow, 2010).

추론(inference)은 청자나 독자가 구어 및 문어에서 구체적으로 명시되지 않은 정보를 추리하는 것이다(Jo \& Lee, 1998). 읽기이해 의 추론은 글자 그 자체를 읽는 기초적인 읽기능력을 뛰어넘어 독 자의 내적 표상을 통해 글 속의 숨어있는 뜻을 파악하도록 하는 요 소이다. 읽기를 할 때 추론능력을 활용하여 사건의 인과관계를 재 정립하며 다음 사건을 예측하고 등장인물의 의도 및 목적을 파악 할 수 있다. 이처럼 읽기과정 내의 추론능력은 핵심적인 이해과정 을 거쳐 심층적 읽기이해 단계로 나아갈 수 있도록 도와주는 요소 이다. 따라서 심층적 읽기이해 단계로 발전하는 초등 고학년 아동 의 추론능력을 살펴봄으로써 읽기성취도를 파악할 수 있다. 즉 읽 기이해를 평가하기 위해선 기초적인 언어능력과 해독, 읽기유창성 및 글 내용을 기억하는 사실적 정보 이해 평가가 필수적이다. 그리 고 글 내용에 관한 적절한 배경지식이 있는지, 추론능력을 활용하 여 글 내용을 유기적으로 연결하여 파악하거나 글 속의 없는 정보 를 추리할 수 있는지 확인해야 한다. 선행연구에서 초등 고학년의 읽기이해 능력을 예측하는 데 추론능력이 큰 비중을 차지한다고 보고하였으며 추론능력을 평가하여 심층적인 읽기이해가 가능한 지 파악하는 것은 중요하다고 한다(Jeong, 2009). 특히 유형에 따라 추론능력을 살펴보고 어떠한 추론에서 취약함을 보이는지 살펴보 아야할 것이다.

추론능력을 학자마다 다르게 체계화하였는데, 공통적으로 추론 을 '텍스트 연결 추론(text-connecting inference)'과 '텍스트 외적 추론(extra-textual inference)'으로 분류하였다. 글 속에 있는 정보 들을 언어적인 단서(접속사, 대용어, 대명사) 통해서 구체적으로 이 해하는 것을 '텍스트 연결 추론'이라고 하고, 글 속에 명시적으로 나타나지 않는 정보를 도출하는 것을 ‘텍스트 외적 추론' 또는 '빠 진 정보 추론(gap-filling inference)'이라고 하였다(Cain \& Oakhill, 1999; Norbury \& Bishop, 2002; Graesser, Singer, \& Trabasso, 1994). 국내 연구에 의하면 읽기부진, 언어학습장애 아동을 대상으로 읽 기과정 안에서 '사실적 정보 이해’와 ‘추론’ 또는 추론을 나누어 ‘텍 스트 연결 추론’과 ‘텍스트 외적 추론’으로 살펴보았는데, 읽기부 진, 언어학습장애 아동은 일반아동에 비해 낮은 추론능력을 보였
다고 한다(Baek, 2013; Jeong, 2009; Kim \& Hwang, 2008). 그러나 최근에는 추론능력을 더 세밀하게 나누어 살펴볼 것으로 강조하여 많은 연구자들이 읽기 내의 추론능력을 더욱 세분화 하여 유형별 로 나누어 살펴보았다(Bowyer-Crane \& Snowling, 2005; Laing \& Kamhi, 2002). 추론능력을 체계화한 명칭은 달랐지만 일반적으로 행동에 대한 원인을 파악하는 추론, 후속사건을 예측하는 추론, 등장인물의 기분/의도/목적을 파악하는 추론으로 나누었다. 이 중 Bowyer-Crane과 Snowling (2005)은 '텍스트 외적 추론'을 '배경지 식을 기반한 추론' '평가적 추론' '정교한 추론’으로 더 세분화하여 글 속의 없는 내용을 추론할 때 독자의 배경지식을 활용하여 이야 기의 다음 내용을 예측할 수 있는지, 등장인물의 기분/의도/목적을 파악할 수 있는지를 확인하였다.

추론능력의 수행력을 살펴보는 것은 중요하지만 전체 수행력만 을 파악하는 것이 아니라 오류 특징을 파악하는 것이 중요하고, 이 를 살펴보는 것은 추론을 실패하는 원인을 파악할 수 있을 수 있다 고 한다(Karasinski \& Ellis Weismer, 2010; Norbury \& Bishop, 2002). 국내의 많은 연구들은 Norbury와 Bishop (2002)의 분류체계를 주 로 사용하였다(Kim \& Pae, 2013; Kim \& Heo, 2004; Yun \& Kim, 2005). Kim과 Pae (2013) 연구에서 초등 고학년이 되면 무응답/모 른다 및 내용 이해실패가 줄지만 초등 고학년 읽기부진 아동들은 질문범주 오류, 추론오류의 비율이 높았다고 한다. 선행연구에서 단순언어장애 아동은 언어학적인 결함으로 추론을 실패하는 '질 문이해 오류, '엉뚱한 대답’이 많았다고 보고되었다(Kim \& Heo, 2004; Yun \& Kim, 2005). 이처럼 오류유형을 살펴보는 것이 추론 에 실패하는 원인을 확인하기 위해 필요하며 아동의 특성을 파악 하는 데 중요는 것을 의미한다.

이후 연구자들은 읽기이해의 어려움을 보이는 아동의 추론능력 에 미흡함이 있다는 것을 바탕으로 이들의 추론오류의 원인을 밝 히기 위해 추론오류 유형을 재정립하여 본 논문에서는 재정립하였 다. 무응답/모른다', '이해실패(failure of literal comprehension)', '표 현 언어의 부족(lack of expressive language/unintelligible)'이 있다. 추론을 하려고 노력하였지만 오류를 보인 경우를 '미숙한 추론 (immature inference)', '틀린 추론(wrong inference)'이라고 한다. 이와 같은 분석 체계로 읽기이해부진아동의 추론 실패 원인을 확 인할 수 있다(Adams, Clarke, \& Haynes, 2009). 텍스트 이해를 위 한 배경지식을 가지고 있는지, 텍스트를 읽는 동안 배경지식을 기 억하고 있는지, 텍스트 정보를 연결할 내용을 적절히 선택하였는 지, 선택한 정보를 배경지식과 잘 통합했는지, 이후 잘못된 결론을 이끌어내지는 않았는지, 추론의 단계에서 어려움이 발생하는지 등 도 파악할수 있다(Jeong, 2009). 
Kyung-Jin Yu, et al. • Inference in Reading in 4-6 Grades with Reading Comprehension Difficulties

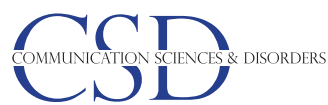

앞서 말한 것처럼 심층적인 읽기이해로 나아가기 위해서는 상위 언어능력, 담화 지식, 추론능력은 필수적이다(Bowyer-Crane \& Snowling, 2005; Cain \& Oakhill, 2007; Snow, 2010). 이 중 한 부분 이라도 붕괴가 일어나면 읽기이해는 실패하게 되며 이런 아동을 읽 기부진(reading disabilities)라고 한다. 읽기부진 아동은 해독의 미 흡함으로 읽기이해의 어려움을 보일 수 있으나 해독능력이 충족되 더라도 낮은 읽기성취도를 보일 수 있다(Catts, Adolf, \& Ellis Weismer, 2006). 이들은 해독능력이 갖추어져 있어 초등 저학년 때는 읽 기부진으로 확인할 수 없으나, 고차원적인 읽기이해가 필요한 초등 고학년이 되어서 읽기부진으로 분류된다고 한다(Cain \& Oakhill, 2007; Kamhi \& Catts, 2012). 이와 같이 읽기이해의 어려움을 보이 는 아동은 언어를 기반으로 한 읽기의 어려움을 보인다고 말하며 DSM-5에서도 확인할 수 있다. DSM-5에서 정의한 특정학습장애 (specific learning disabilities)는 읽기, 쓰기, 수학에 어려움을 보이 는 아동이라고 정의하며, 이 중 읽기장애 아동은 해독 및 읽기유창 성의 어려움을 보이거나 언어이해를 포함한 읽기이해의 어려움을 보이는 아동으로 정의한다. 성공적인 읽기이해를 위해서는 해독뿐 아니라 언어적 이해능력이 필수적이다. 그리고 초등 고학년의 경우 심층적인 읽기이해로 나아가기 위해 담화 도식에 대한 지식 및 추 론능력이 필요하며 이 능력의 미흡함을 보이는 경우에 낮은 읽기이 해 능력에 영향을 미친다고 할 수 있다. 초등 읽기부진 아동의 특성 을 살펴보았을 때 초등 저학년과 고학년 모두 읽기이해의 어려움을 보였고, 초등 고학년의 경우 일반아동과 비교하였을 때 해독에서 는 유의한 차이를 보이지 않았다는 것이 이러한 사실을 뒷받침 해 준다(Kim, 2012).

읽기이해는 해독, 언어적 이해력이 필요하지만 심층적 읽기이해 로 나아가기 위해서는 추론능력이 필수적이다. 특히 추론능력은 초 등 고학년의 읽기이해 능력을 예측하는 요소이며 선행연구에서 읽 기이해부진아동은 기본적인 해독 및 문장 이해력을 갖추었지만 이 러한 상위수준의 언어처리능력에 어려움을 보인다고 한다(Kim \& $\mathrm{Kim}, 2006)$. 따라서 초등 고학년 읽기이해부진아동은 읽기과정 내 추론의 어려움이 낮은 읽기이해 능력에 영향을 미친다고 할 수 있 을 것이다. 추론능력을 텍스트 연결 추론, 빠진 정보 추론으로 나누 어 살펴보는 국내 연구들은 많았지만 더 세밀하게 분석하여 살펴 보는 연구는 부족하였다. 또한 언어학습장애 및 읽기부진 아동의 읽기과정 내의 추론능력을 살펴보는 연구들도 있었지만 실제 초등 고학년 읽기이해부진아동을 대상으로 한 논문은 부족하였다. 따라 서 본 연구에서는 초등 고학년 읽기집단의 이야기 글 읽기 시 유형 에 따른 추론능력과 오류 특성을 확인함으로써 읽기이해부진아동 의 추론능력을 파악하고 중재방향에 도움을 줄 수 있을 것이다.
연구 문제는 다음과 같다.

1) 읽기집단과 유형에 따른 초등 고학년 아동의 추론능력은 어떠 한가?

2) 읽기집단과 오류유형에 따른 초등 고학년 아동의 추론오류는 어떠한가?

\section{연구방법}

\section{연구대상}

본 연구는 부산시 소재의 초등 고학년(4-6학년)에 재학 중인 읽 기이해부진아동 19 명과 학년 및 거주지를 일치시킨 일반아동 19 명 으로 총 38명(4학년 각 6명, 5학년 각 6명, 6학년 각 7명)을 대상으로 하였다.

읽기이해부진아동은 부모나 교사에 의해 신체, 정서, 청력에 문 제가 없다고 보고되었고 한국 비언어 지능검사(K-CTONI-2; Park, 2014)의 도형척도 지능지수가 80 (평균 하) 이상으로 정상범위에 속 하며, 한국어 읽기검사(KOLRA; Pae, Kim, Yoon, \& Jang, 2015)의 읽기이해 표준점수가 90 이하로 읽기부진에 속하고, 해독과 읽기유 창성 표준점수 91 이상으로 자동적 읽기가 가능하고 심층적 읽기 이해로 나아가는 단계에 있는 읽기이해부진아동을 선정하였다.

일반아동은 부모나 교사에 의해 신체, 정서, 청력에 문제가 없다 고 보고되었고 한국 비언어 지능검사(K-CTONI-2; Park, 2014)의 도형척도 지능지수가 80 (평균 하) 이상이며, 수용·표현어휘력 검사 (REVT; Kim, Hong, Kim, Jang, \& Lee, 2009)의 수용어휘력 검사 결과 $-1 \mathrm{SD}$ 이상으로 정상 수준의 수용어휘력을 보이고, 한국어 읽 기검사(KOLRA; Pae et al., 2015)의 모든 영역에서 표준점수 91 이 상으로 정상에 속하는 아동을 대상으로 선정하였다(Table 1).

Table 1. Means of standardized tests for children with reading comprehension difficulties and normally developing children

\begin{tabular}{lcc}
\hline & $\begin{array}{c}\text { Children with reading } \\
\text { comprehension difficulties } \\
(\mathrm{N}=19)\end{array}$ & $\begin{array}{c}\text { Normally developing } \\
\text { children } \\
(\mathrm{N}=19)\end{array}$ \\
\hline $\begin{array}{l}\text { K-CTONI-2 }^{\mathrm{a}} \\
\text { KOLRA }^{\mathrm{b}}\end{array}$ & $91.05(7.96)$ & $100.79(9.75)$ \\
Decoding & $100.53(6.89)$ & $107.42(5.98)$ \\
Reading fluency & $101.05(8.41)$ & $103.05(8.75)$ \\
Reading comprehension & $79.00(9.64)$ & $105.42(8.47)$ \\
\hline
\end{tabular}

K-CTONI-2 = Korean version of Comprehensive Test of Nonverbal Intelligence Second Edition (Park, 2014); KOLRA=Korean Language Based Reading Assessment (Pae, Kim, Yoon, \& Jang, 2015).

${ }^{\mathrm{a}} \mathrm{Q}$, ${ }^{\mathrm{b}}$ standard score. 


\section{연구도구}

본 연구에서 사용된 연구도구는 선행연구 Norbury와 Bishop (2002), Yoon (2004)의 'Beach story' Karasinski와 Ellis Weismer (2010)의 'The Girl and the Alligator', 'The Donkey and the Wolf', 'The King's Ducks'의 이야기 글을 참고하여 번안하고 수정하였다. 글은 일상이야기 1편, 상상이야기 3편으로 총 4편을 구성하였으며, 번역 한 뒤에 영어식 문장을 한국어에 맞도록 바꾸고 이야기 구성 력을 높이기 위해서 내용 및 어휘를 생략하거나 추가하였다.

추론유형은 Bowyer-Crane과 Snowling (2005)이 구성한 개념적 유형에 따라 분류하였다. '사실적 정보 이해'는 글에 드러난 내용을 기억하고 이해하는 과제이고, ‘응집성 추론’은 글 속의 언어적 단서 를 이해하여 문장 간 정보를 연결하는 추론이다. '배경지식을 기반 한 추론'은 글 내용을 부분적으로 이해하고 독자의 배경지식을 활 용하여 글 속에 없는 내용을 파악하는 추론이고, '평가적 추론'은 글 속의 등장인물의 감정, 의도, 목적을 파악하는 것이다. 그리고 '정교한 추론'은 글 이후의 사건을 예측하거나 글 내용과 관련이 적 은 상황으로 대입하여 추론하는 것이다(Appendix 1). 이와 같이 '사실적 정보 이해'와 4 가지 추론으로 분류하였고 각 유형별로 9 개 문항으로 총 추론 질문은 45 문항을 제작하였다. 이야기 글과 추론 검사의 문항 예시는 Appendix 2에 제시하였다.

4 개의 이야기 글과 45 개의 추론과제를 구성한 후 언어병리학 박 사로, 학령기 평가 및 중재를 한 경험이 있는 1 급 언어치료사 1 인과 언어병리학 교수 2 인에게 내용 타당도를 의뢰하였다. 항목에 대한 타당도는 5 점 척도로 검증 $(0$, 매우 타당하지 않음; 1 , 타당하지 않 음; 2, 보통; 3 타당함; 4 , 매우 타당함)받아 타당도에서 2점 이하의 점수를 받은 항목이나 이야기 글 내 어색한 부분은 제외 및 수정하 였다. 추론유형 분류체계 타당도는 3.67점, 오류유형 분류체계 타 당도는 4점으로 높은 타당도를 보였다. 또한 이야기 글(길이, 구성, 내용, 어휘)에 대한 타당도는 3.45점, 이야기 글의 추론질문에 대한 타당도는 3.92점으로 나타났다. 모든 영역에서 타당함과 매우 타당 함 사이에 속해 높은 타당도를 검증 받았다.

검사는 조용한 장소에서 검사자와 아동이 1:1로 진행하였다. 먼 저 한국 비언어성 지능검사와 한국어 읽기검사를 통해 본 연구대 상의 선정조건에 적합한지의 여부를 판단한 뒤에 연구대상으로 선 정된 아동은 본 연구 실험과제를 실시하였다. 아동에게 연구자가 고안한 추론과제의 이야기 글을 제공하고 아동에게 "선생님이 주 는 글을 마음 속으로 읽는 거야. 다 읽고 나면 선생님이 질문을 할 테니까 다 보면 말해줘.”라고 하여 이야기 글을 묵독할 수 있도록 한다. 이후 “선생님이 이 글에 대해서 몇 가지 질문을 할 건데, 기억 해서 답 해줘도 되고 모르겠으면 보고 해줘도 돼.”라고 하여 과제를
이해할 수 있도록 충분히 설명한 뒤에 검사를 실시하였다. 아동의 반응은 모두 녹음하였으며 검사 2 일 안에 전사 및 분석하였다.

\section{자료분석}

추론검사는 아동이 적절한 대답을 한 경우 1점, 오반응을 보인 경우 0 점으로 처리하여 원점수를 산출하였다. 각 추론유형별 점수 는 9점이며 총 점수는 45 점을 만점으로 하였다. 오반응 보인 문항 을 오류유형에 따라 분석하였는데, 이때 오류유형은 Adams 등 (2009)의 기준에 따라 다섯 가지로 나누었다. '무응답/모른다'는 질 문에 대답하지 않거나 모른다고 대답하는 경우이며, ‘이해실패’는 글 내용, 질문의 언어적 요소를 파악하지 못해 추론을 시도하지 못 한 것으로 분석하였다. 그리고 추론을 할 수 있지만 글의 내용을 바 탕으로 너무 집약적이거나 포괄적으로 대답한 경우를 '미숙한 추 론’으로 분석하였고 '틀린 추론’은 독자의 배경지식으로만 추론한 경우를 말한다. '표현 언어 부족'은 적절한 추론은 하였지만 부적절 한 어휘, 구문의 사용하여 내용전달이 미숙한 경우를 말한다(Appendix 3).

수집한 자료의 신뢰도를 검증하기 위해 전체 자료 $20 \%$ (읽기이 해부진아동 4 명, 일반아동 3 명)의 평가자 간 신뢰도를 산출하였다. 연구자는 제 1 평가자이고, 학령기 평가 및 중재의 경험이 있고 언어 병리를 전공한 대학원 졸업생 1 명을 제 2 평가자로 선정하였다. 신뢰 도 측정은 추론과제에 대한 채점신뢰도와 오류유형에 대한 분석신 뢰도를 구하였다. 채점신뢰도는 $94.60 \%$ 로 나타났고, 오류유형에 대 한 분석신뢰도 결과는 $90.15 \%$ 로 높은 신뢰도를 보였다.

\section{자료의 통계처리}

읽기집단(읽기이해부진/일반아동)과 추론유형(사실/응집성/배 경지식/평가/정교)에 따른 수행력을 살펴보기 위해 이원혼합분산 분석(two-way ANOVA with repeated measure)을 실시하였고 집 단 내 변인과 상호작용 효과에 대한 사후분석은 독립/대응 $t$-검정 을 실시하였다. 통계 처리는 SPSS Statistics 21 프로그램을 이용하 여 분석하였다. 오반응을 보인 문항을 오류유형(무응답, 모른다/이 해실패/틀린 추론/미숙한 추론/표현 언어 부족)에 따라 나누었다. 그리고 각 오류유형에서 아동이 보인 오류빈도를 전체 오류 빈도 로 나누고 100을 곱하여 오류유형별 오류율을 산출하였다.

\section{연구결과}

\section{읽기집단과 유형에 따른 추론능력의 차이 비교}

읽기집단 간 읽기 시 추론능력을 살펴본 결과 $F_{(1,36)}=40.317(p<$ 
.05)로 읽기이해부진아동은 일반아동보다 유의하게 낮은 추론능 력을 보였다. 추론유형에 따른 차이는 $F_{(4,144)}=34.046(p<.05)$ 으로 나타나 유형 간 추론능력의 유의한 차이가 있는 것으로 나타났다 (Table 1). 이러한 차이를 사후분석으로 살펴보았을 때, 사실적 정 보 이해는 유의하게 높은 수행력을 보였으며 평가적 추론은 다른 추론유형에 비해 유의하게 낮은 수행력을 보였다. 그리고 배경지식 을 기반한 추론, 응집성 추론, 정교한 추론 간의 유의한 차이는 보 이지 않았다.

읽기집단과 유형에 따른 추론능력의 차이는 $F_{(4,144)}=8.117(p<.05)$ 로 상호작용 효과가 나타났다. 상호작용에 대한 사후분석을 실시 하였을 때, 읽기이해부진아동은 일반아동에 비해 모든 추론유형 에서 유의하게 낮은 수행력을 보였다. 읽기집단 내에서 추론유형에 따른 차이를 살펴보면, 읽기이해부진아동은 사실적 정보 이해, 응 집성 추론, 배경지식을 기반한 추론, 정교한 추론, 평가적 추론 순 으로 유의하게 높은 수행력을 보였다. 이와 달리 일반아동은 사실 적 정보 이해, 배경지식을 기반한 추론, 정교한 추론 순으로 수행력 을 나타냈다. 그리고 응집성 추론, 평가적 추론 순으로 유의하게 높 은 수행력을 보였다(Table 2, Figure 1).

Table 2. Descriptive statistics of inference in reading by subgroup

\begin{tabular}{lccc}
\hline & $\begin{array}{c}\text { Children with read- } \\
\text { ing comprehension } \\
\text { difficulties }(\mathrm{N}=19)\end{array}$ & $\begin{array}{c}\text { Normally devel- } \\
\text { oping children } \\
(\mathrm{N}=19)\end{array}$ & $\begin{array}{c}\text { Total } \\
(\mathrm{N}=38)\end{array}$ \\
\hline Literal information & $6.32(1.85)$ & $7.58(1.50)$ & $6.95(1.78)$ \\
Cohesive inference & $4.89(1.28)$ & $6.53(1.54)$ & $5.71(1.62)$ \\
Knowledge based inference & $4.05(2.04)$ & $7.47(1.02)$ & $5.76(1.78)$ \\
Evaluative inference & $2.79(1.98)$ & $5.16(1.21)$ & $3.97(2.02)$ \\
Elaborative inference & $3.68(1.60)$ & $7.26(1.14)$ & $5.47(2.53)$ \\
Total & $4.34(1.75)$ & $6.80(1.28)$ & $5.57(1.94)$ \\
\hline
\end{tabular}

Values are presented as mean (SD).

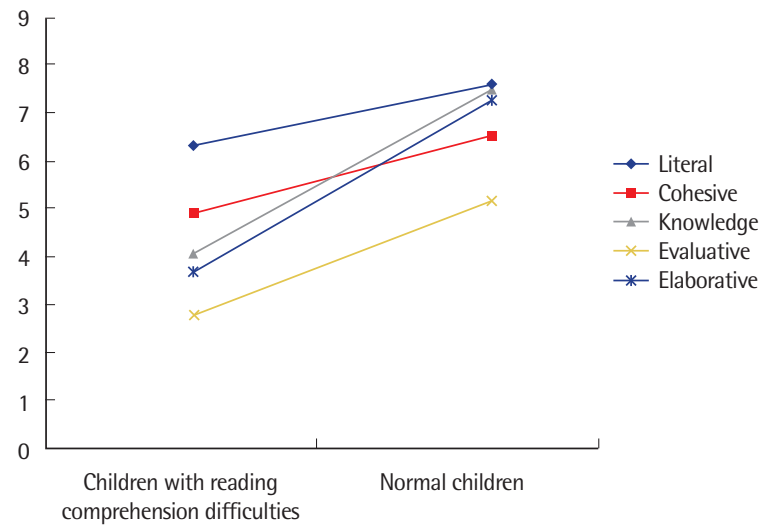

Figure 1. Descriptive statistics of inference in reading by subgroup.

\section{읽기집단과 추론오류유형에 따른 추론오류 비교}

읽기이해부진아동과 일반아동의 이야기 글 읽기 시 추론오류유 형을 살펴본 결과, 읽기이해부진아동은 미숙한 추론, 이해실패, 틀 린 추론, 무응답/모른다, 표현 언어 부족의 순으로 높은 오류율을 보였다. 일반아동은 미숙한 추론, 틀린 추론, 무응답/모른다, 이해 실패, 표현 언어 부족 순으로 높은 오류율을 보였다. 두 읽기집단 모 두 미숙한 추론, 틀린 추론이 높은 비율이 나타났고 표현 언어 부 족은 가장 낮은 비율이었다. 일반아동은 미숙한 추론과 틀린 추론 이 $80 \%$ 이상이었으며 읽기이해부진아동은 $65 \%$ 로 가장 높은 비율 을 보였고 표현 언어 부족은 두 집단 모두 약 $4 \%$ 로 가장 낮은 비율 이었다. 하지만 일반아동은 무응답/모른다, 이해실패로 인한 추론 오류가 각 5\%정도 낮은 비율을 보인 반면 읽기이해부진아동은 무 응답/모른다가 $13 \%$, 이해실패가 $15 \%$ 의 비율을 보였다(Table 3 , Figure 2).

Table 3. Error rates of inference error pattern by subgroup (\%)

\begin{tabular}{lccc}
\hline & $\begin{array}{c}\text { Children with read- } \\
\text { ing comprehension } \\
\text { difficulties }(\mathrm{N}=19)\end{array}$ & $\begin{array}{c}\text { Normally de- } \\
\text { veloping chil- } \\
\text { dren }(\mathrm{N}=19)\end{array}$ & $\begin{array}{c}\text { Total } \\
(\mathrm{N}=38)\end{array}$ \\
\hline No response & $13.90(18.58)$ & $5.72(10.56)$ & $9.81(5.78)$ \\
Failure of literal comprehension & $15.25(11.20)$ & $5.40(7.76)$ & $10.32(6.95)$ \\
Wrong inference & $13.99(10.84)$ & $12.83(13.65)$ & $13.41(0.82)$ \\
Immature inference & $52.46(19.05)$ & $72.02(18.49)$ & $62.24(35.66)$ \\
Lack of expressive language & $4.39(7.75)$ & $4.01(7.17)$ & $4.20(0.268)$ \\
Total & 100 & 100 & 100 \\
\hline
\end{tabular}

Values are presented as mean (SD).

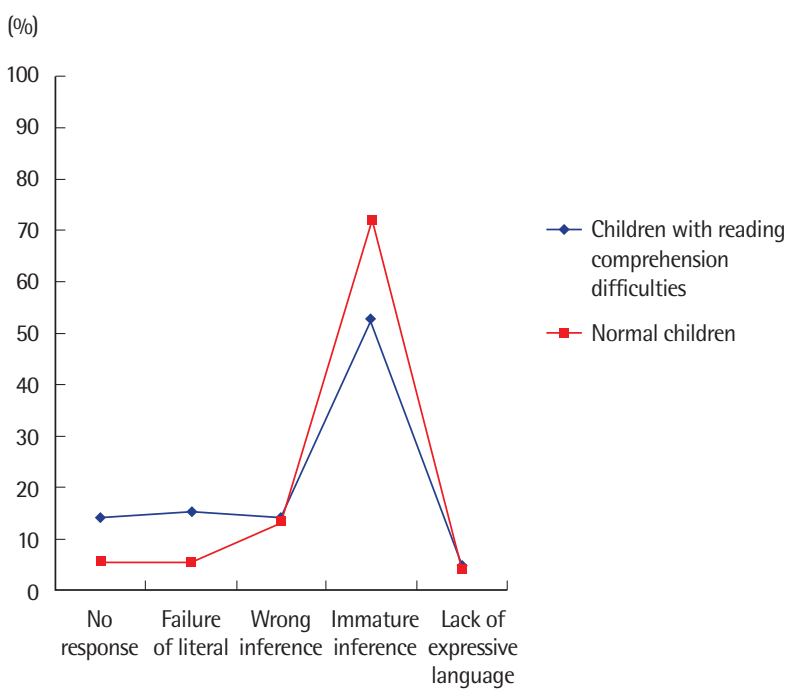

Figure 2. Error rates of inference error pattern by subgroup. 


\section{논의 및 결론}

본 연구는 이야기 글 읽기과정 안에서 초등 고학년 읽기이해부 진아동의 추론능력을 유형에 따라 확인하고 추론오류를 구체적으 로 살펴보아 읽기이해를 위한 추론능력을 확인하고자 하였다. 그 결과에 따른 논의는 다음과 같다.

첫째, 읽기이해부진아동과 일반아동의 추론능력을 살펴본 결과 읽기이해부진아동은 일반아동보다 유의미하게 낮은 추론능력을 보였다. 본 연구에서 읽기이해부진아동은 고학년이며 해독과 읽기 유창성의 표준점수가 91점, 백분위 점수 $25 \%$ ile이상으로 자동적 읽 기가 가능하고 학습을 위한 읽기가 가능했다. 즉, 본 연구의 읽기이 해부진아동은 유창하게 읽을 수 있어, 심층적 읽기이해로 나아가 는 단계에 속했지만, 추론의 어려움으로 심층적 읽기이해로 나아가 지 못하는 것으로 나타났다. 선행연구에서 읽기 과정의 추론능력 이 읽기이해와 관련이 있다고 하였다(Jeong, 2009). 그렇다면 읽기 이해부진아동의 읽기성취도는 추론능력의 영향을 받는 다는 것을 의미한다.

둘째, 유형에 따른 추론능력을 살펴본 결과 추론유형 간 유의한 차이가 나타났다. 사실적 정보 이해는 다른 추론유형에 비해 유의 하게 높은 수행력을 보였고, 그 다음으로 배경지식을 기반한 추론, 응집성 추론, 정교한 추론 순으로 높은 수행력을 보였다. 그리고 평 가적 추론은 다른 추론유형에 비해 유의하게 낮은 수행력을 보였 다. 사실적 정보 이해는 글에 드러난 내용을 파악하는 것으로, 다 른 추론과제보다 높은 수행력을 보여 글 속에 드러난 정보를 파악 하는 것이 가장 쉬운 과제라는 것을 알 수 있었다. 특히 초등 고학년 시기에는 사실적 정보 이해를 바탕으로 글 속에 있는 정보를 파악 하는 핵심적 읽기이해가 가능하여 심층적 읽기이해 단계로 나아갈 준비가 되었다는 것을 시사한다. 또한 본 연구의 초등 고학년 일반 아동은 글 내의 정보를 연결하는 질문, 글의 일부분을 이해하고 배 경지식을 활용하여 새로운 정보를 추론하는 질문에서 비슷한 수행 력을 보였다. 이를 보아 글의 드러난 정보를 파악하는 것보다 낮은 수행력을 보였지만, 글 속의 정보를 연결하여 글 내용을 구체화하 는 추론과 자신의 배경지식을 활용하여 글 속에 없는 정보를 추론 하는 것은 유사한 정도라는 것을 알 수 있었다. 그런데 평가적 추론 은 다른 추론유형에 비해 유의하게 낮은 수행력을 보였고 그 격차 도 컸다. 초등 고학년이 되어 추론을 활용하여 글 내용을 심층적으 로 이해할 수 있는데 다른 추론에 비해 전반적인 내용을 파악하고 등장인물의 기분 및 느낌을 파악하는 추론과제는 어렵다는 것을 의미한다. 평가적 추론은 등장인물의 기분, 느낌, 의도를 파악하는 것으로 전반적인 맥락 이해가 필수적이고 전체 내용을 이해하고 독
자의 평가가 추가된 개념으로 텍스트 외적 추론의 확장된 개념이라 고 하며(Alonzo, Basaraba, Tindal, \& Carriveau, 2009; BowyerCrane \& Snowling, 2005), 다른 추론유형보다 어려운 추론과제라 는 선행연구를 지지하는 바이다(Alonzo et al., 2009; Kintsch \& Rawson, 2005; Kim, Kim, \& Sung, 2013).

셋째, 읽기집단과 유형에 따른 읽기 내 추론능력을 살펴 본 결과 상호작용 효과가 나타났다. 읽기집단과 유형에 따른 추론능력을 자 세히 살펴본 결과, 읽기이해부진아동은 모든 유형에서 일반아동보 다 낮은 수행력을 보였다. 사실적 정보 이해 과제에서도 읽기이해부 진아동은 일반아동에 비해 낮은 수행력을 보였다. 즉 읽기이해부진 아동은 여러 개의 단락으로 이루어진 이야기 글을 읽고 드러난 정 보를 이해하거나 기억하는 데 어려워한다는 것이다. 선행연구에서 는 읽기이해부진아동과 일반아동 간의 사실적 정보 이해에서는 유 의한 차이가 없었다고 하지만(Bowyer-Crane \& Snowling, 2005), 여러 단락으로 이루어진 글을 이용한 선행연구에서는 읽기이해부 진아동과 일반아동 간의 사실적 정보 이해 과제에서 유의한 차이 를 보였다(Baek, 2013; Jeong, 2009). 본 연구의 읽기이해부진아동 은 해독 및 읽기유창성이 $25 \%$ ile 이상으로 자동적 읽기가 가능했 지만 여러 단락으로 이루어진 글을 읽고 글에 드러난 내용을 확인 하는 것이 어려워했다. 독자는 사실적 정보 이해를 바탕으로 한 핵 심적 읽기이해가 가능해지고 이후 추론능력을 활용하여 글에 없 는 내용을 도출하는 심층적 읽기이해로 나아간다. 그런데 읽기이해 부진아동은 글에 드러난 내용 파악이 어렵기 때문에 이를 바탕으 로 한 심층적인 읽기이해로 나아가는 데 어려움을 보일 수 있다. 따 라서 초등 고학년 읽기이해부진아동이 사실적 정보 이해는 가능하 다고 섣불리 판단하면 안되며 중재를 할 때 사실적 정보 이해를 반 드시 고려해야 한다는 것을 시사한다.

그리고 읽기이해부진아동은 일반아동에 비해 응집성 추론, 배 경지식 기반한 추론, 정교한 추론, 평가적 추론에서 모두 유의하게 낮은 수행력을 보였다. 추론능력은 글의 정보를 연결하고, 글에 없 는 내용을 파악할 수 있도록 한다. 특히 본 연구의 읽기이해부진아 동은 해독 및 읽기유창성이 정상 범위에 속해 자동적인 해독을 할 수 있고 읽기이해에 더 큰 비중을 둘 수 있음에도 불구하고 읽기이 해 내에 낮은 추론능력을 보였다. 이를 보아 읽기이해부진아동은 글을 구체적으로 이해하고 글에 없는 내용까지 파악하는 데 어려 운 것으로 나타났다.

두 읽기집단 모두 평가적 추론이 가장 낮고 다른 추론유형과도 큰 격차를 보였다는 공통점이 있다. 이것은 읽기집단 모두 다른 추 론유형에 비해 평가적 추론이 어렵다는 것을 의미한다. 평가적 추 론은 글을 읽고 전반적인 맥락 이해를 하고 등장인물의 의도, 기분 
에 대한 평가가 포함되어야 하는 추론(Bowyer-Crane \& Snowling, 2005)으로, 텍스트 외적 추론에서 확장된 개념이라고 할 수 있다. 초등 고학년은 심층적인 읽기이해를 시작하는 시기이지만, 등장인 물의 내적 반응을 평가하는 추론은 다른 유형에 비해 미숙하다고 해석할 수 있다. 특히 읽기이해부진아동은 일반아동과 평가적 추 론에서 큰 격차를 보였는데 이는 글의 구조를 확인하고 등장인물 의 기분, 의도를 파악하는 데 어렵기 때문에 나타나는 현상이다. 따 라서 글의 구조와 인물의 구성요소를 조절하고 추론의 유형을 고 려하여 중재계획을 세울 필요가 있다.

읽기집단 내에서 추론과제 수행력 차이를 살펴보면 읽기이해부 진아동은 사실적 정보 이해, 응집성 추론, 배경지식을 기반한 추론, 정교한 추론, 평가적 추론 순으로 유의하게 높은 수행력을 보였다. 읽기이해부진아동은 일반아동과 달리 응집성 추론보다 배경지식 을 기반한 추론과 정교한 추론에서 더 낮은 수행력을 보였다. 이를 보아 언어적 단서를 통해 문장을 연결하여 정보를 도출하는 것보다 글 내용과 자신의 배경지식을 통합하여 새로운 정보를 추론하는 과제를 더 어려워한다는 것을 알 수 있었다. 이 결과는 선행연구에 서 읽기이해부진아동이 연결추론보다 빠진 정보 추론에서 더 큰 어려움을 보인다는 것을 지지한다(Cain \& Oakhill, 1999; Carlson. S. E. et al., 2014). 이야기 중재 방법 중 QART (Question Answer Relationship Techniques; Raphael, 1984)는 쉬운 질문부터 점차 어려운 질문을 하여 이야기를 이해하도록 돕는 것이다. 질문의 난이도를 살펴보면 사건을 연결하는 질문보다 배경지식 및 경험을 활용하도 록 하는 질문이 상위의 질문으로 사건을 연결하는 추론보다 배경 지식을 활용하여 빠진 정보를 추론이 더 어렵다는 것이다. 이와 함 께 본 연구결과는 읽기이해 중재 시 문장, 문단, 사건을 연결하는 추 론과제와 아동의 배경지식과 글 내용을 통합하여 새로운 정보를 도출하는 과제의 난이도를 설정하고 단계적으로 접근할 필요가 있 다는 것을 뒷받침한다.

마지막으로 읽기집단의 추론과제 내 오류 특징을 살펴본 결과 읽기이해부진아동은 일반아동과 유사한 오류패턴을 보였다. 두 읽 기집단 모두 미숙한 추론과 틀린 추론에서 높은 오류율을 보였고 표현 언어 부족은 낮은 오류율을 보였다. 특히 일반아동은 미숙한 추론과 틀린 추론이 $80 \%$ 이상, 읽기이해부진아동은 미숙한 추론 과 틀린 추론이 $60 \%$ 이상으로 글을 읽고 추론을 할 수 있지만 추론 한 내용이 너무 집약/포괄적이거나 글 내용과 배경지식을 통합하지 못한 것으로 나타났다. 이를 보아 읽기이해부진아동은 일반아동과 마찬가지로 글을 읽고 추론을 시도하지만 많은 아동들이 추론에 실패하는 것을 알 수 있었다. 그리고 두 읽기집단 모두 표현 언어 부 족이 $4 \%$ 로 매우 낮은 비율로 자신의 생각을 짧은 문장으로 전달할
때 부적절한 어휘를 쓰거나 구문의 오류를 보이는 것은 드물었다. 따라서 초등 고학년이 되면 읽기이해부진아동도 일반아동과 같이 읽기이해에서 추론오류로 부적절한 대답을 하는 경우가 많지만 자 신의 생각을 적절한 어휘 및 문법으로 표현하지 못하는 것은 아니 었다.

그런데 일반아동은 이해실패, 무응답/모른다고 대답하는 경우 는 각 $5 \%$ 로 낮은 비율을 보였지만 읽기이해부진아동은 이해실패 가 약 $15 \%$, 무응답/모른다의 경우 약 $13 \%$ 로 일반아동보다 높은 비 율이 나타났다. 이는 읽기이해부진아동은 일반아동에 비해 글 내 용 및 질문을 이해하지 못해 엉뚱한 대답, 질문 범주에 벗어난 대답 을 하는 경우가 많다는 것이다. 따라서 읽기이해부진아동은 핵심 적 읽기이해의 부족함으로 추론 실패를 경험하는 경우가 종종 있 을 것으로 보인다.

선행연구를 살펴보면 구어에서 읽기부진아동은 일반아동과 유 사한 오류 패턴을 보이며 일반아동의 상당수가 초등 고학년이 되어 서도 미숙한 추론의 질문범위 오류와 틀린 추론의 추론오류가 절 반 이상의 비율을 차지한다고 하였다(Kim \& Pae, 2013). 또한 묵독 에서 이야기 읽기이해의 추론오류를 분석하였을 때 일반아동은 미숙한 추론과 틀린 추론이 약 $54 \%$ 였고 읽기이해부진아동의 미숙 한 추론과 틀린 추론은 약 $37 \%$ 로 나타났다. 그리고 일반아동의 표 현능력 부족은 $9 \%$ 였으나, 읽기이해부진아동은 $29 \%$ 로 높은 비율 을 보였다(Jang \& Lee, 2016). 이는 연구의 평가방법의 차이로 인해 서 상의한 결과가 도출된 것으로 보인다. 본 연구결과를 종합적으 로 살펴보아 초등 고학년이 되면 이야기 글을 읽고 추론 오류로 인 한 미숙한 추론, 틀린 추론 하는 경우가 가장 많고 글의 내용 또는 질문을 이해하지 못해서 엉뚱한 대답을 하거나 질문 범주에 벗어 난 대답을 하는 것은 드물었다. 그러나 읽기이해부진아동은 일반 아동보다 글이나 질문을 이해하지 못해 엉뚱한 대답, 질문 범주에 벗어난 대답을 하는 경우가 많았다. 이러한 결과를 토대로 초등 고 학년 읽기이해부진아동의 중재 시 어휘, 문법이나 추론 자체에 대 해서만 중재하는 것이 아니라 글을 읽고 문장, 문단, 사건의 관계를 알도록 하고 글의 구조를 파악하며 언어적 추론을 향상시키는 중 재 방법이 필요하다.

본 연구의 읽기이해부진아동은 자동적 읽기가 가능하여 이해 단계에 초점이 맞춰져 있는 아동을 대상으로 하였지만 이야기 글 읽고 구어로 대답하는 모든 추론과제에서 일반아동에 비해 낮은 수행력을 보여, 여러 문단으로 이루어진 글을 읽고 드러난 내용을 파악하는 것은 미흡한 것을 알 수 있었다. 자세히 살펴보면 읽기이 해부진아동은 사실적 정보 이해, 응집성 추론, 배경지식을 기반한 추론, 정교한 추론, 평가적 추론 순으로 유의하게 높은 수행력을 보 
였고, 일반아동은 사실적 정보 이해, 배경지식을 기반한 추론, 정교 한 추론 순으로 수행력을 보였고 응집성 추론, 평가적 추론 순으로 유의하게 높은 수행력을 보였다. 읽기이해부진아동은 일반아동과 달리 응집성 추론보다 배경지식을 기반한 추론, 정교한 추론에서 더 낮은 수행력을 차이를 보여 글 속의 언어적 지식을 활용하여 문 장을 연결해 이해하는 과제보다 자신의 배경지식을 활용하여 글 내용과 통합하는 과제를 더 어려워하는 것을 알 수 있었다. 이러한 결과를 토대로 읽기 중재 시에 읽기이해부진아동의 사실적 정보 이 해를 반드시 고려해야 하며 문장 및 문단을 연결하는 추론과제부 터 독자의 배경지식을 활용하여 독자의 배경지식과 글 내용을 통 합하는 추론과제까지 단계적으로 질문을 실시하여 텍스트를 이해 를 촉진하여야 할 것이다. 또, 두 읽기집단 모두 글의 구조를 파악하 고 등장인물의 기분, 의도를 파악하는 평가적 추론을 가장 어려워 하는 것으로 나타나 초등 고학년 아동은 심층적 읽기이해 단계에 접어들었으나 글의 전반적인 내용을 이해하여 등장인물의 기분, 의 도를 파악하는 읽기과제는 아직 미흡한 것으로 나타났다. 이야기 글 읽기 시 추론오류 패턴을 분석한 결과 두 읽기집단 모두 미숙한 추론, 틀린 추론에서 절반 이상의 높은 비율을 보였고 표현 언어의 부족은 $4 \%$ 이하로 낮은 비율을 보여 유사한 오류패턴을 보였다. 즉 읽기이해부진아동도 일반아동과 마찬가지로 글 내용 바탕으로 추 론을 하려고 노력하지만 무응답/모른다, 이해실패가 높은 비율을 보여 사실적 정보 이해도 미숙하다는 것을 알 수 있었다. 이러한 연 구결과는 아동의 추론의 미숙함을 단순히 전반적인 수행력을 통 해 판단하는 것에 그치는 것이 아니라 추론오류를 자세히 살펴보 고 그에 적절한 중재가 이루어져야 할 것을 시사한다. 본 연구는 고 학년을 대상으로 하였기 때문에 저학년이라면 읽기이해에서 추론 능력이 어떤지 살펴볼 필요가 있으며, 본 연구에서는 읽기이해와 추론능력의 실질적인 상관능력을 살펴보지 않아 이 둘의 관계를 살펴보는 후속연구가 필요하다.

\section{REFERENCES}

Adams, C., Clarke, E., \& Haynes, R. (2009). Inference and sentence comprehension in children with specific or pragmatic language impairments. International Journal of Language \& Communication Disorders, 44, 301-318.

Alonzo, J., Basaraba, D., Tindal, G., \& Carriveau, R. S. (2009). They read, but how well do they understand? An empirical look at the nuances of measuring reading comprehension. Assessment for Effective Intervention, 35, $34-44$.

Baek, J. E. (2013). The abilities of inference in children with language learning disorders; reading, listening, watching animation modalities (Master's thesis). Ewha Womans University, Seoul, Korea.

Bowyer-Crane, C., \& Snowling, M. J. (2005). Assessing children's inference generation: what do tests of reading comprehension measure? British Journal of Educational Psychology, 75, 189-201.

Cain, K., \& Oakhill, J. (1999). Inference making ability and its relation to comprehension failure. Reading and Writing, 11, 489-503.

Cain, K., \& Oakhill, J. (2007). Children's comprehension problems in oral and written language: a cognitive perspective. New York, NY: Guilford Press.

Cain, K., Oakhill, J., \& Bryant, P. (2004). Children's reading comprehension ability: concurrent prediction by working memory, verbal ability, and component skills. Journal of Educational Psychology, 96, 31-42.

Catts, H. W., Adlof, S. M., \& Ellis Weismer, S. (2006). Language deficits in poor comprehenders: a case for the simple view of reading. Journal of Speech, Language, and Hearing Research, 49, 278-293.

Chall, J. S. (1983). Stages of reading development. New York, NY: McGraw-Hill. Graesser, A. C., Singer, M., \& Trabasso, T. (1994). Constructing inferences during narrative text comprehension. Psychological Review, 101, 371-395.

Hoover, W. A., \& Gough, P. B. (1990). The simple view of reading. Reading and Writing, 2, 127-160.

Jang, H. S., \& Lee, E. J. (2016). Reading comprehension of narrative text in poor comprehenders of 5 th grade by reading methods. Korean Journal of Special Education, 50, 15-176.

Jeong, M. R. (2009). Inferencing in poor comprehenders in grades three to six. Journal of Speech \& Hearing Disorders, 18, 51-64.

Kamhi, A. G., \& Catts, H. W. (2012). Language and Reading Disabilities (3rd ed.). Boston, MA: Pearson.

Karasinski, C., \& Ellis Weismer, S. (2010). Comprehension of inferences in discourse processing by adolescents with and without language impairment. Journal of Speech, Language, and Hearing Research, 53, 1268-1279.

Kim, A. H., \& Hwang, M. (2008). Prediction of reading skills in upper elementary students. Korean Journal of Communication Disorders, 13, 1-25.

Kim, A. H., \& Kim, U. J. (2006). Comprehension monitoring and reading comprehension in low-achieving students and normally-achieving students, Journal of Special Education: Theory and Practice, 7, 101-119.

Kim, A. H., Kim, U. J., \& Sung, S. Y. (2013). A study of the reading comprehension characteristics of $1 \mathrm{st}, 3 \mathrm{rd}$, and 5th grade students: focusing on higher-order reading comprehension processes. The Journal of Elementary Education, 26, 21-42.

Kim, J. S., \& Heo, I. (2004). The characteristics of inferencing failure in hear- 
ing impairment children with different levels of reading comprehension proficiencies. Journal of Speech \& Hearing Disorders, 13, 79-92.

Kim, M. (2012). Text comprehension and word recognition of Korean elementary school children with or without reading difficulties (Doctoral dissertation). Hallym University, Chuncheon, Korea.

Kim, M., \& Pae, S. (2013). Listening and reading comprehension skills of korean elementary school children with reading difficulties. Communication Sciences \& Disorders, 18, 392-401.

Kim, Y. T., Hong, G. H., Kim, K. H., Jang, H. S., \& Lee, J. Y. (2009). Receptive \& expressive vocabulary test (REVT). Seoul: Seoul Community Rehabilitation Center

Laing, S. P., \& Kamhi, A. G. (2002). The use of think-aloud protocols to compare inferencing abilities in average and below-average readers. Journal of Learning Disabilities, 35, 437-448.

Norbury, C. F., \& Bishop, D. V. (2002). Inferential processing and story recall in children with communication problems: a comparison of specific language impairment, pragmatic language impairment and high-functioning autism. International Journal of Language \& Communication Disorders, 37,
227-251.

Pae, S., Kim, M., Yoon, H. J., \& Jang, S. (2015). Korean Language Based Reading Assessment (KOLRA). Seoul: Hakjisa.

Park, H. (2014). Korean version of Comprehensive Test of Nonverbal Intelligence Second Edition (K-CTONI-2). Seoul: Mind Press.

Raphael, T. (1984). Teaching learners about sources of information for answering comprehension questions. Journal of Reading, 27, 202-311.

Rawson, K. A., \& Kintsch, W. (2005). Rereading effects depend on time of test. Journal of Educational Psychology, 97, 70-80.

Snow, C. E. (2010). Reading comprehension: reading for learning. In P. Peterson et al. (Eds.), International encyclopedia of education (3rd ed., pp. 413418). Oxford, UK: Elsevier.

Yun, H. R. (2004). Story comprehension and retelling abilities in school-age children with specific language impairment (Doctoral dissertation). Ewha Womans university, Seoul.

Yun, H. R., \& Kim, Y. T. (2005). Story comprehension abilities in school-age children with specific language impairment. Korean Journal of Communication Disorders, 10, 41-56. 
Appendix 1. Type of inference

\begin{tabular}{ll}
\hline 추론유형 & \multicolumn{1}{c}{ 정의 } \\
\hline 사실적 정보 이해(literal information) & 추론능력을 사용하지 않고 글에 드러난 내용을 기억하고 이해하는 과제이다. \\
& 글 속의 언어적 단서(접속사, 지시어)를 이해하여 문장 간 정보를 연결하는 추론이다. 즉, 문장을 연결하여 \\
응집성 추론(cohesive inference) & 구체적인 정보를 확인하는 것이다. \\
& 글 내용을 부분적으로 파악하고, 내용과 독자의 배경지식을 연결하고 글 속에서 명시적으로 밝혀지지 않은 \\
배경지식을 기반한 추론(knowledge base inference) & 의미를 파악하는 추론이다. \\
& 글 속 등장인물의 감정과 관련 있는 추론으로 주인공의 감정, 의도, 목적을 파악하는 것이다. 즉, 전반적인 \\
& 펙스트 내용은 필수적어억ㅁㅕㅕ 추리에 독작의 배경지식 및 평가가 필요한 추론이다. \\
& 글 이후의 사건을 예측하거나 글 내용과 관련이 적은 새로운 상황일 때 적절하게 추론하는 것이다. 이 추론은 \\
& 텍스트 내용 이해에 직접적으로 영향을 미치지 않지만 텍스트 내용을 좀 더 풍부하게 만들어 주는 것으로 \\
& 독자의 내적 표상이 필요하다.
\end{tabular}

Appendix 2. Example of items for inference task

\section{은지의 주말이야기}

장마가 끝난 어느 토요일 오후에 은지는 경수와 물놀이를 갔어요. 두 친구가 그 곳에 도착했을 때 둘은 매우 목이 말랐어요. 경수는 자기 가방에서 음료수를 꺼내서 은지에게 나눠 주었어요. 오렌지 쥬스는 아주 시원했어요.

은지는 화장실에 들어가 파란 원피스를 벗고 수영복으로 갈아입었어요. 그런데 파도가 너무 심해서 물놀이를 할 수 없었어요. 그래서 물놀이 대신에 모래성 쌓기 를 했어요. 두 친구는 오후 내내 정신 없이 노느라고 다른 일들을 모두 잊어버렸어요.

갑자기 은지는 오늘이 은지 동생의 생일인 것이 기억났어요. 은지 집에서 보통 7시에 저녁을 먹지만, 특별한 날에는 한 시간 일찍 식사를 해요. 은지는 얼른 수영복 을 벗어서 수건 안에 둘둘 말아 배낭 속에 집어넣었어요. 그런 다음 서둘러 옷을 갈아입고 집으로 출발했어요. 그들은 있는 힘껏 최대한의 속도로 페달을 밟았어요. 집에 도착했을 때 은지는 매우 피곤했지만 저녁식사 시간을 정확히 맞출 수 있었어요. 벌써 다른 가족들은 모두 식탁 둘러 앉아 있었어요. 은지는 얼른 자기 방으로 들어가 책상 서랍 안에서 미리 포장해 놓은 크레파스를 꺼냈어요. 은지가 "유후”하고 안도의 한숨을 쉬었어요.

1) 사실적 이해 질문 : 은지와 경수는 무슨 요일에 물놀이를 갔나요?

2) 응집성 추론 질문 : 은지는 몇 시에 집에 도착했을까요?

3) 배경지식을 기반으로 한 추론 질문 : 누가 케이크에 불을 껐을까요?

4) 평가적 추론 질문 : 집으로 가는 동안 은지의 기분은 어떠했을까요?

5) 정교한 추론 질문 : 만약 은지엄마의 생신이었다면 어떤 선물을 했을까요? 
Kyung-Jin Yu, et al. • Inference in Reading in 4-6 Grades with Reading Comprehension Difficulties

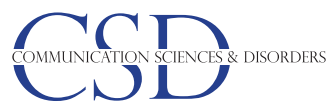

Appendix 3. Type of inference error

\begin{tabular}{|c|c|}
\hline 추론오류유형 & 정의 \\
\hline 무응답/모른다(no response) & 대답을 하지 않거나 ‘모른다’라고 대답한 오류를 말한다. \\
\hline 이해실패(failure of literal comprehension) & $\begin{array}{l}\text { 질문 또는 텍스트의 내용을 정확히 이해하지 못해 보인 오류를 말한다. 예를 들어 ‘첫째 돼지는 주변에 쉽게 구할 수 } \\
\text { 있는 지푸라기로 집을 지었다.'의 문장에 대한 질문으로 ‘첫째 돼지는 무엇으로 집을 지었나요?’라는 질문에 ‘저녁에 } \\
\text { 지었어요.', '돼지다.'라고 질문 범주에 벗어나거나 엉뚱한 대답을 하는 경우이다. }\end{array}$ \\
\hline 틀린 추론(wrong inference) & $\begin{array}{l}\text { 독자의 배경지식, 경험을 활용하여 추론하지만 텍스트와 관련 없이 추론을 하여 보인 오류를 말한다. 예를 들어 ‘지푸 } \\
\text { 라기 집이 늑대의 입김에 무너져 내리는 것을 보고 둘째 돼지는 나무 집을 지었습니다.'라는 문장에 대한 ‘둘째 돼지는 } \\
\text { 왜 나무로 집을 지었을까?’라는 질문에 '나무 집이 더 멋져서.라고 독자의 배경지식을 활용하여 추론하였지만, 텍스트 } \\
\text { 와 배경지식을 통합하여 추론하지 못한 경우라고 할 수 있다. }\end{array}$ \\
\hline 미숙한 추론(immature inference) & $\begin{array}{l}\text { 텍스트 내용을 이해하고, 독자의 배경지식 및 경험을 바탕으로 추론을 하려고 하지만 내용이 과도하게 자세하거나 모 } \\
\text { 호한 경우를 들 수 있다. 예를 들어 ‘아기 돼지 삼형제’ 내용 중에서 ‘벽돌집이 무너지지 않은 이유는 무엇일까요?’라고 } \\
\text { 묻는 경우 ‘벽돌집이 튼튼해서’라고 대답하지 못하고 ‘벽돌집이 지푸라기 집보다 안 무너져요.'라고 하는 경우로 텍스 } \\
\text { 트 내용을 토대로 추론을 하였지만 정확한 대답을 추론하지 못하는 경우를 말한다. }\end{array}$ \\
\hline 표현 언어의 부족(lack of expressive language) & $\begin{array}{l}\text { 부적절한 어휘를 사용했거나 구문의 오류로 인해서 내용 전달이 미숙한 경우이다. 예를 들어 ‘벽돌집은 늑대의 입김, } \\
\text { 발차기, 주먹질에도 무너지지 않았습니다.'라는 문장의 질문으로 ‘벽돌집이 무너지지 않은 이유는 무엇일까요?라는 } \\
\text { 질문에 ‘집이 땅땅해서’' '이게 그렇게나 무너지지 않고 그래요.라고 추론을 적절히 했다고 판단은 되지만 부적절한 어 } \\
\text { 휘를 사용하거나 구문의 미흡함으로 정확한 내용 전달이 어려운 경우를 말한다. }\end{array}$ \\
\hline
\end{tabular}




\section{국문초록}

\section{초등 고학년 읽기이해부진아동의 유형에 따른 추론능력과 오류 특성 \\ 유경진 ${ }^{1}$ 김미배 ${ }^{2}$ \\ ${ }^{1}$ 부산가톨릭대학교 대학원 언어청각치료학과, ${ }^{2}{ }^{\circ}$ 산가톨릭대학교 언어청각치료학과}

배경 및 목적: 본 연구는 초등 고학년 읽기이해부진아동의 읽기 내 추론능력을 유형에 따라 살펴보고 오류 특성을 확인하여 읽기이해 부진아동의 평가 및 중재에 대한 시사점을 제공하고자 하였다. 방법: 본 연구는 학년과 거주지를 일치시킨 초등 고학년(4-6학년) 읽기 이해부진아동과 일반아동 각 19 명으로 총 38 명을 대상으로 하였다. 추론 과제는 이야기 글 4 개를 읽고 5 개의 추론유형 질문에 답하는 것으로 질문은 총 45 문항을 구성하였다. 결과: 첫째, 읽기이해부진아동의 추론능력은 일반아동보다 유의하게 낮았다. 둘째, 두 읽기집 단의 추론능력을 살펴보면 사실적 정보 이해가 유의하게 높은 수행력을 보였고 배경지식을 기반한 추론, 응집성 추론, 정교한 추론 순 으로 수행력이 높았다. 평가적 추론은 유의하게 낮은 수행력을 보였다. 셋째, 읽기집단과 추론유형에 따른 상호작용 효과가 나타났다. 넷째, 오류패턴을 살펴보면 두 읽기집단 모두 ‘미숙한 추론' ‘틀린 추론’의 비율은 높고 ‘표현 언어 부족'의 비율은 가장 낮아 유사한 패턴 을 보였다. 그러나 읽기이해부진아동은 '이해실패’와 ‘무응답/모른다'에서 일반아동보다 높은 비율을 보였다. 논의 및 결론: 초등 고학 년 읽기이해부진아동은 읽기 내 추론과제에서 어려움을 보였으며 이는 심층적인 읽기이해를 하는 데 영향을 미칠 수 있을 것이다. 따라 서 본 논문의 결과는 읽기이해부진아동의 추론능력을 유형에 따라 살펴보았고 오류 특징을 구체적으로 살펴보아 읽기이해부진아동의 평가 및 중재의 시사점을 제공한다.

핵심어: 읽기이해부진아동, 읽기이해, 추론, 추론유형, 오류유형

본 논문은 2017년 제1저자의 석사학위 논문을 수정 및 보완하였음.

\section{참고문헌}

김미배(2012). 이해와 낱말재인을 중심으로 본 초등 읽기부진 아동 특성. 한림대학교 대학원 박사학위논문. 김미배, 배소영(2013). 학년에 따른 읽기부진 아동의 듣기 및 읽기이해능력. 언어청각장애연구, 18, 392-401. 김애화, 김의정(2006). 읽기부진학생의 읽기이해점검력 및 읽기이해 특성 연구. 특수교육저널: 이론과 실천, 7, 101-119. 김애화, 김의정, 성소연(2013). 초등학교 1,3,5학년 학생의 읽기이해 특성 연구: 상위 읽기이해 처리 특성을 중심으로. 초등교육연구, 26, 21-42. 김애화, 황민아(2008). 초등학교 고학년의 읽기능력에 영향을 미치는 읽기관련 변인에 관한 연구. 언어청각장애연구, 13, 1-25. 김영태, 홍경훈, 김경희, 장혜성, 이주연(2009). 수용·표현 어휘력검사(REVT). 서울: 서울장애인종합복지관. 김지숙, 허일(2004). 읽기 이해 능력에 따른 청각장애 아동의 추론 실패 특성분석. 언어치료연구, 13, 79-92. 박혜원(2014). 한국 비언어지능검사2판(K-CTONI-2). 서울: 마인드프레스. 배소영, 김미배, 윤효진, 장승민(2015). 한국어 읽기검사(KOLRA). 서울: 학지사. 백재은(2013). 이야기 과제 양식(읽기, 듣기, 애니메이션 보기)에 따른 언어학습장애의 추론 능력. 이화여자대학교 대학원 석사학위논문. 윤혜련, 김영태(2005). 학령기 단순언어장애아동의 이야기 이해특성. 언어청각장애연구, 10,41-56. 장현숙, 이은주(2016). 읽기방식에 따른 초등학교 5학년 읽기이해 부진학생의 이야기 글 이해능력. 특수교육학연구, 50, 159-176. 정미란(2009). 초등학교 3-6학년 읽기이해부진 학생의 이야기 글 읽기 이해: 사실적 정보이해와추론. 언어치료연구, 18, 51-64. 정미란(2013). 초등학교 3-6학년 읽기이해부진학생의 읽기이해력 예측변인 탐색. 학습장애연구, 10, 79-103. 황진애, 김영태, 이주연(2007). 학령기 아동의 읽기이해력 발달: 중심내용파악, 참조 및 추론능력을 중심으로. 언어청각장애연구, 12, 412-428. 